\title{
BMJ Open Exploring correlates of depression, quality of life and alcohol misuse: a nationwide cross-sectional study of international migrants during the COVID-19 epidemic in China
}

\author{
Brian J Hall, ${ }^{1,2}$ Peizhen Zhao (1) , ${ }^{3,4}$ Ming Zhou Xiong (1) , ${ }^{3,4}$ Carl Latkin, ${ }^{2}$ \\ Bin Yang, ${ }^{3,4}$ Cheng Wang (i) ${ }^{3,4}$
}

To cite: Hall BJ, Zhao $P$, Xiong MZ, et al. Exploring correlates of depression, quality of life and alcohol misuse: a nationwide crosssectional study of international migrants during the COVID-19 epidemic in China. BMJ Open 2021;11:e048012. doi:10.1136/ bmjopen-2020-048012

- Prepublication history and additional material for this paper is available online. To view these files, please visit the journal online (http://dx.doi.org/10. 1136/bmjopen-2020-048012)

BJH and PZ contributed equally.

Received 16 December 2020

Revised 23 February 2021

Accepted 23 February 2021

D Check for updates

(C) Author(s) (or their employer(s)) 2021. Re-use permitted under CC BY-NC. No commercial re-use. See rights and permissions. Published by BMJ.

For numbered affiliations see end of article.

Correspondence to

Dr Cheng Wang;

wangcheng090705@gmail.com

\section{ABSTRACT}

Objectives The COVID-19 pandemic has overwhelmed health systems globally. With the increase of global migration, quantifying the health needs and key correlates of these outcomes is a global health priority. This study assessed migration characteristics, COVID-19 attitudes and the postmigration social environment as key correlates of depression, quality of life and alcohol misuse among international migrants in China.

Design A nationwide cross-sectional online survey was conducted from 17 February and 1 March 2020.

Setting Links to the online survey were disseminated by migrant-focused community-based organisations through WeChat.

Participants English speaking international migrants who met the inclusion criteria. Inclusion criteria were being born in a country outside of China, aged 18 years or over, cumulatively living in China for 1 month or more and staying in China between December 2019 and February 2020.

Outcome measures Depression, quality of life and alcohol misuse.

Results Regression models indicated that planning or considering leaving China due to COVID-19, lacking the confidence to protect themselves and not being confident that the epidemic would end soon was associated with greater depression, lower quality of life and greater levels of alcohol misuse. Worry about contracting COVID-19 and feeling helpless to prevent infection were associated with greater depression and lower quality of life. General perceived social support, and trust in Chinese people, institutions and systems were protective factors for depression and associated with higher reported quality of life. Conclusions This study identifies key correlates that, if adequately addressed through public health outreach, may safeguard migrant well-being during a public health emergency. Trust in people and systems within the postmigration environment is an important consideration for future public health planning efforts.

\section{INTRODUCTION}

The COVID-19 epidemic began in December 2019 in Wuhan, Hubei, China, and rapidly
Strengths and limitations of this study

- This nationwide cross-sectional study of international migrants in China is the first study known to assess symptoms of depression, alcohol misuse and quality of life among migrants during a public health emergency.

- The sampling of migrants using social media provided wide coverage of migrants hailing from more than 70 countries who were in China during the COVID-19 epidemic.

- The cross-sectional nature of the design limits causal inference.

- The study was conducting following the onset of the COVID-19 outbreak, and therefore, preoutbreak mental health is not known.

spread across the country. The WHO declared a Public Health Emergency of International Concern on 30 January 2020, and a pandemic on 11 March 2020. ${ }^{1}$ Widespread uncertainty and fear about the virus and its lethality predominated the early period leading up to these declarations. Social distancing, quarantines and reduced economic activity are associated with increased burden of common mental disorders and substance misuse at the population level. ${ }^{2}$ The epidemic highlighted the potential inequalities in health status, especially among the most vulnerable in society, including international migrants, who may be at increased risk of poor mental health during a public health emergency. ${ }^{3} 4$ The current study is the first known to assess well-being and substance misuse in a national sample of international migrants during the COVID-19 pandemic.

Population migration increased dramatically in recent years, and now over 250 million people are living outside their 
home countries. ${ }^{5}$ Migrants are exposed to adversities and adverse postmigration social environments known to increase the burden of mental ill health. ${ }^{6}$ This is especially true in 'south-south' migration, where an estimated 73 million people ${ }^{7}$ move between countries in the global south. Migration to China in particular has increased in the past decade, primarily motivated by economic, educational and cultural exchange opportunities. ${ }^{89}$ Two major forces encouraging this migration is the Forum on China-African Cooperation ${ }^{10}{ }^{11}$ and the Belt and Road Initiative, which aims to enhance China's relationships with countries regionally and across the world (Institute for Security and Development Policy). While China has become a destination for international migrants, ${ }^{9}$ 12-14 limited information is known about their health and well-being.

The social determinants of health, a broad health framework, suggests that the quality of the social and structural environments within which migrants live, exert influences on their overall health and well-being. The recent Lancet Commission on Migration and Health highlighted several key social determinants including factors related to migration, living and working conditions and interactions with the host population. ${ }^{6}{ }^{15}$ According to a systematic review of 24000 migrants sampled across 35 studies, the overall pooled prevalence of common mental disorders was $20.0 \% .{ }^{16}$ Migrants are at higher risk of mental ill health compared with non-migrant populations living in host countries. This key inequality in population wellbeing challenges health systems and takes an economic toll on the host country. In China, international migrants experience substantial barriers to health services and may also experience discrimination, worsening their wellbeing. ${ }^{6} 17-19$

During public health emergencies, the mental health of the general population is affected, ${ }^{20}{ }^{21}$ but few studies specifically explore the mental health and well-being of migrant populations in these contexts. The limited data available suggest that these events disproportionately affect migrants relative to host country communities, ${ }^{22}$ and these data are inadequate to inform public health planning and preparedness for this population. ${ }^{23}$ Public health responses are often focused on citizens; therefore, migrant populations may be excluded. Data are crucially needed that highlight the needs of diverse and vulnerable populations, including migrants, in order to inform public health emergency response and preparedness.

In this study, we addressed critical gaps in knowledge related to international migrant well-being during public health emergencies. We assessed depression, quality of life (QoL) and alcohol misuse as outcomes. Migration characteristics, COVID-19 attitudes, and the postmigration social environmental influences were evaluated as correlates. We used the migrant health and social determinants frameworks to inform our selection of key correlates expected to influence the well-being of international migrants during the pandemic. ${ }^{24}$

\section{METHODS}

\section{Study design and participants}

An online cross-sectional survey was conducted between 17 February and 1 March 2020. Links to the online survey were disseminated by migrant-focused communitybased organisations $(\mathrm{CBO})$ through WeChat (a popular Chinese messaging app). It was hosted by WenJuanXing (Changsha Haoxing Information Technology Co, Ltd, China). The survey questionnaire was available in English and created based on discussions with CBO stakeholders, policymakers and experts on international migrants. English is the common language among international migrants from diverse countries of origin living in China. The survey was pilot tested with 20 international migrants to ensure the survey was clear and well understood by our target population. These pilot data were excluded in the final analysis.

All participants who clicked the link for the survey were screened for eligibility. Inclusion criteria were: being born in a country outside of China, aged 18 years or over, cumulatively living in China for 1 month or more and staying in China between December 2019 and February 2020. The survey was restricted to one phone number and a single device to minimise the risk of people participating multiple times.

\section{Main outcomes \\ Depressive symptoms}

Depressive symptoms were measured by the Centre for Epidemiologic Studies Depression Scale (CES-D). The CES-D scale is a 20 -item self-report inventory. ${ }^{25}$ Each item is scored $0-3$ on a Likert-type scale for a frequency of depressive symptoms in the last week and summed for a total score range of $0-60$. Higher scores indicate greater symptom severity. The CES-D demonstrated good internal consistency in this study (Cronbach's alpha: 0.88).

\section{Quality of life}

QoL was measured by the WHO Quality of Life (WHOQOL-BREF) and is composed of 26 items. ${ }^{26}$ It has been validated in several migrant populations. ${ }^{27-30}$ The WHOQOL-BREF measures the following broad domains: physical health (seven items), psychological (six items), social relationships (three items) and environment (eight items) and two items that measure overall QOL and general health. Following scoring conventions, the items were coded from 1 to 5 , and the total scores were converted to a $0-100$ scale, with higher score indicating better QoL. In the current study, the Cronbach's alpha for the scale was 0.93 .

\section{Alcohol use}

Alcohol use was measured with two items from the WHOAUDIT $^{31}$ (WHO. The Alcohol Use Disorders Identification Test, 2010), including the frequency of drinking alcoholic beverages and the number of drinks consumed on a typical day. These items were summed, with higher scores indicating greater alcohol misuse. 


\section{Correlates}

Migration characteristics included region of origin, purpose of migration (business, study and employment), cumulative length of stay in China and cumulative length of stay in China during the epidemic outbreak period (from December to February).

Attitude towards the COVID-19 epidemic were answered on a four-point Likert-type scale ranging from strongly disagree to strongly agree and included confidence of protecting themselves from contracting COVID19 , worry that they or their friends or loved ones will contract COVID-19, helplessness to prevent COVID-19 and confidence that the epidemic would end soon. One additional question asked whether they will return to their home country due to the epidemic, with no, yes or unsure response options.

\section{Social environment}

Perception of Chinese people's attitude towards foreigners was measured with a single item on a 5-point Likert scale ranging from 1 'very unfriendly' to 5 'very friendly'.

Perceived social support was measured by the Multidimensional Scale of Perceived Social Support (MSPSS). ${ }^{32}$ The MSPSS contains 12 items, reflecting support from family, friends and significant others, with each domain consisting of four items rated on a seven-point Likerttype scale, ranging from 1: 'very strongly disagree' to 7: 'very strongly agree'. Total scores range from 12 to 84, with higher scores indicating greater perceived social support.

\section{Trust towards Chinese institutions and groups during the COVID-19 outbreak}

Trust towards Chinese institutions and groups included eight items ${ }^{13}$ : the Central Government, the department that is responsible for health, the department that handles immigration, the hospital system, doctors and medical professionals, the information you are receiving about the COVID-19, the police and the Chinese people. The scoring of each item of the scale ranged from 0 to 100 with intervals of 10 . A score of 0 implies no trust at all, and 100 indicates complete trust. All items were summed for an overall trust score. Each item and the total score were trichotomised into low, medium and high trust.

Participant characteristics included gender, age, marital status, educational attainment, annual income, living arrangement in China, religion, health insurance, infectious diseases experience, diagnosis with COVID19 , history of mental illness and past year mental health treatment.

\section{Statistical analysis}

We report descriptive statistics for the distribution of the sample regarding social demographic, attitude towards the COVID-19 epidemic, social support, depressive symptoms, QoL and alcohol use.

Univariate and multivariable linear regressions were performed to explore correlates of depressive symptoms, QoL and alcohol use. Multivariable models evaluating migration characteristics, attitudes towards the COVID-19 epidemic and the social environment were adjusted for gender, age, marital status, education, income, living arrangement, religion, health insurance, infectious disease in past year, diagnoses with COVID-19, past diagnosis with mental disorder and past year treatment for mental health conditions, which were selected a priori as potential confounders. Due to the large number of students who were included in our sample, we conducted a sensitivity analysis with the student subgroup to explore whether the patterns of findings in the overall sample were robust. Statistical significance was set at $\mathrm{p}<0.05$ for model coefficients. Analyses were performed using SAS V.9.4.

\section{Patient and public involvement}

The participants and general public were not involved in the development of the research question, outcome measures, design, recruitment and conduct of this study.

\section{RESULTS}

The survey platform was accessed by 2494 people. Ninetyfive people did not provide informed consent. Among the remaining 2399 individuals, 973 did not meet eligibility requirements (355 were born in China, 522 were less than 18 years old, 28 cumulatively lived in China less than 1 month and 68 did not stay in China during COVID-19 outbreak). A total of 1362 individuals completed the online survey (see figure 1 and online supplemental table 1), originating from 77 countries and 6 continents (see online supplemental table 2). The measures of trust in Chinese institutions and groups was deleted by the survey platform after responses were recorded from 868 individuals due to political sensitivity.

The majority of participants were male (60.9\%), between 16 and 35 years old $(89.8 \%)$, never married $(87.5 \%)$, had a college degree or higher $(57.9 \%)$, had an annual income less than US\$2000 (63.4\%) and originated from African countries (74.7\%). More than half migrated for study $(64.0 \%)$. The majority stayed in China for the entire 3-month epidemic period between December 2019 and February $2020(79.5 \%)$. Most were not diagnosed with COVID-19 (99.0\%) (see table 1).

Most individuals were confident in knowing how to protect themselves from COVID-19 (89.0\%), not worrying about themselves (58.0\%) contracting COVID-19, not feeling helpless to prevent COVID-19 (64.7\%) and most were confident that the COVID-19 epidemic would end soon $(88.1 \%)$. However, more than half $(58.2 \%)$ reported worrying about loved ones/friends contracting COVID19. The majority did not plan to leave China due to COVID-19 (66.8\%). Most reported that Chinese people had friendly attitudes towards them $(65.0 \%)$, and a little more than half reported a high level of trust in Chinese people, systems and institutions $(52.5 \%)$.

\section{Correlates of depression}

The average depressive symptom severity was 17.7 $(\mathrm{SD}=11.2)$. In multivariable models, greater depressive 


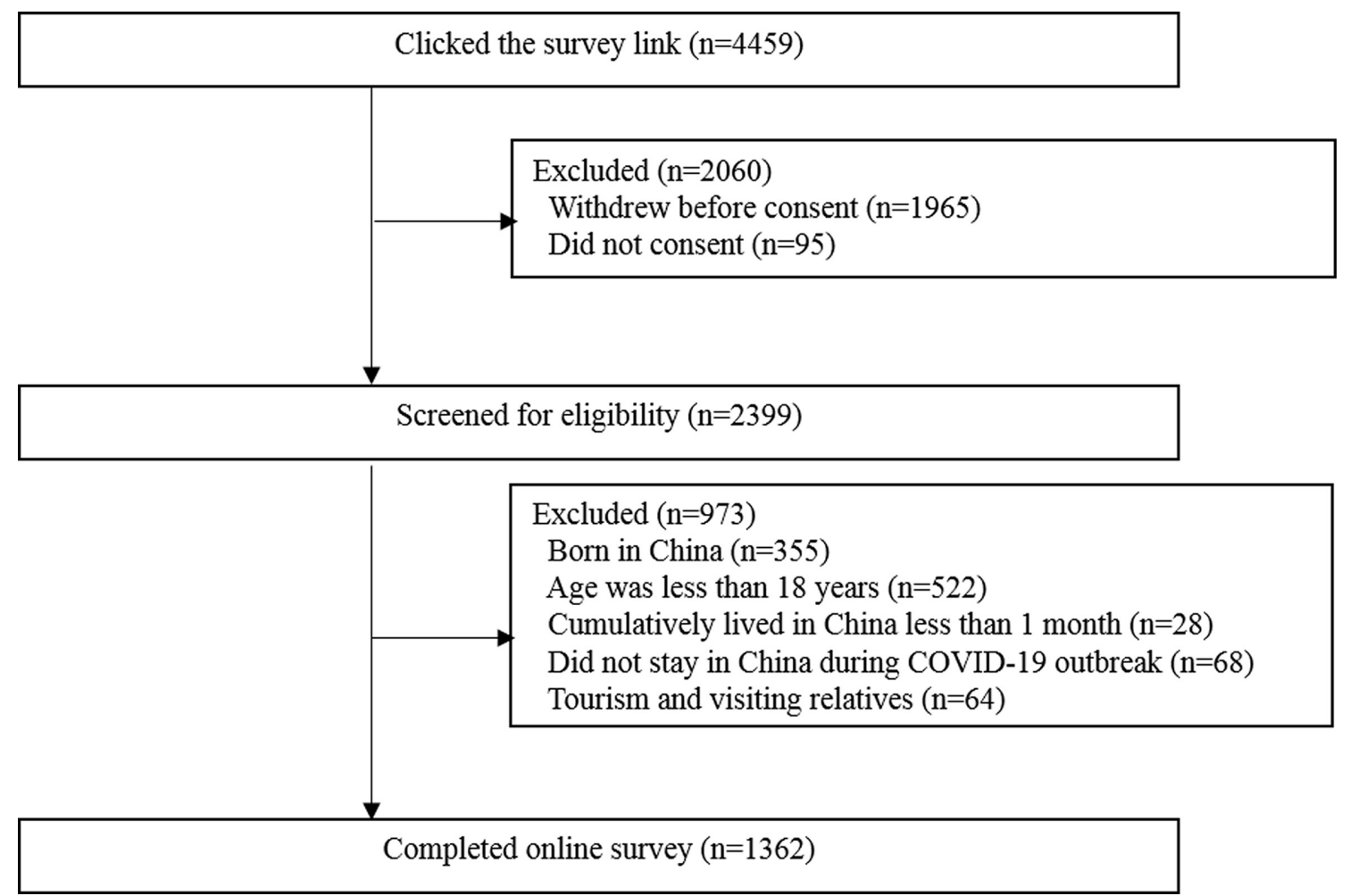

Figure 1 Flow chart.

symptom severity was significantly associated with country of origin, with people from non-Asian countries reporting lower depressive symptoms when compared with African migrants. Compared with students, people who migrated for business reported greater depressive symptom severity. Among attitudes towards the COVID-19 epidemic, planning to leave China, or being unsure about leaving China, not being confident to protect themselves, worry about contracting COVID-19 themselves and about loved ones contracting COVID-19, feeling helpless to prevent COVID-19 and not being confident the epidemic would end soon were all associated with greater depressive symptom severity. Friendly attitudes from Chinese people and greater social support were associated with lower depressive symptom severity. The pattern of findings for trust was consistent across Chinese people, systems and institutions such that high levels of trust were associated with lower depressive symptom severity (see table 2 ).

\section{Correlates of QoL}

The total score of the WHOQOL-BREF scale was

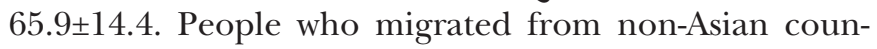
tries reported greater QoL compared with migrants from African countries. For attitudes towards the COVID-19 epidemic, planning to leave China or being unsure about leaving China, not being confident to protect themselves, worry about contracting COVID-19 themselves, feeling helpless to prevent COVID-19 and not being confident the epidemic would end soon were all associated with lower QoL. Friendly attitudes from Chinese people and greater social support were associated with greater QoL. The pattern of findings for trust was consistent across measured variables such that high levels of trust were associated with greater QoL (see table 2).

\section{Correlates of alcohol misuse}

People who migrated from Asian countries reported less alcohol misuse compared with migrants from African countries. Compared with students, people who migrated for business reported lower alcohol misuse. For attitudes towards the COVID-19 epidemic, planning to leave China or being unsure about leaving China, not being confident to protect themselves and not being confident the epidemic would end soon were associated with increased alcohol misuse. Social support, friendly attitudes from Chinese people and trust were not associated with alcohol misuse in this sample (all ps >0.11) (see tables 2 and 3).

\section{Sensitivity analysis for student subsample}

The general pattern of results for the student subsample were similar to the overall migrant sample (see online supplemental table 3). No notable differences were observed for the QoL outcome. However, unlike in the overall sample, among students, being married/engaged was associated with greater depression, and income, having health insurance, having an infectious disease in the past year were not statistically related to depressive symptoms. In addition, and in contrast to the overall sample, students who had COVID-19, a history of mental disorder diagnosis or treatment in the past year and were not confident to protect themselves were not statistically related to alcohol use, and being married/engaged was associated with less alcohol use. Higher reported social support was associated with lower alcohol misuse. 
Table 1 Participant characteristics of international migrants in a nationwide cross-sectional survey in China, 2020 $(n=1362)$

\begin{tabular}{|c|c|}
\hline Variable & $\mathbf{N}(\%)$ \\
\hline \multicolumn{2}{|l|}{ Gender } \\
\hline Male & $830(60.9)$ \\
\hline Female & $532(39.1)$ \\
\hline \multicolumn{2}{|l|}{ Age (years) } \\
\hline $16-25$ & $877(64.4)$ \\
\hline 26-35 & $346(25.4)$ \\
\hline $36-45$ & $125(9.2)$ \\
\hline$>45$ & $14(1.0)$ \\
\hline \multicolumn{2}{|l|}{ Marital status } \\
\hline Never married & $1192(87.5)$ \\
\hline Married/engaged & $170(12.5)$ \\
\hline \multicolumn{2}{|l|}{ Educational attainment } \\
\hline High school or below & 417 (30.6) \\
\hline Some college & $156(11.5)$ \\
\hline Bachelor's degree and above & 789 (57.9) \\
\hline \multicolumn{2}{|l|}{ Annual income (US\$) } \\
\hline$<\$ 2000$ & $864(63.4)$ \\
\hline$\$ 2000-\$ 5000$ & $245(18.0)$ \\
\hline$\$ 5000-\$ 10000$ & $120(8.8)$ \\
\hline$>\$ 10000$ & $133(9.8)$ \\
\hline \multicolumn{2}{|l|}{ Living arrangement in China } \\
\hline Hotel & $70(5.1)$ \\
\hline Guest apartment & $27(2.0)$ \\
\hline Purchased apartment & $9(0.7)$ \\
\hline Rental apartment & $473(34.7)$ \\
\hline Staff/student dormitory & $762(55.9)$ \\
\hline No fixed residence & $21(1.5)$ \\
\hline \multicolumn{2}{|l|}{ Religion } \\
\hline Christianity & $892(65.5)$ \\
\hline Islam & $303(22.2)$ \\
\hline Buddhism & $14(1.0)$ \\
\hline Other & $51(3.7)$ \\
\hline None & $102(7.5)$ \\
\hline \multicolumn{2}{|l|}{ Health insurance in China } \\
\hline No & $1149(84.4)$ \\
\hline Yes & $213(15.6)$ \\
\hline \multicolumn{2}{|l|}{ Infectious disease (past year) } \\
\hline No & $1015(74.5)$ \\
\hline Yes & 347 (25.5) \\
\hline \multicolumn{2}{|c|}{ Being diagnosed with the COVID-19 } \\
\hline No & $1349(99.0)$ \\
\hline Yes & $13(1.0)$ \\
\hline Past mental disorder diagnosis & \\
\hline
\end{tabular}

Continued
Table 1 Continued

\begin{tabular}{ll}
\hline Variable & N (\%) \\
\hline No & $1303(95.7)$ \\
Yes & $59(4.3)$
\end{tabular}

Mental health treatment (past year)

No 1301 (95.5)

Yes $61(4.5)$

Migration characteristics

Region of origin

$\begin{array}{ll}\text { Asia } & 308(22.6) \\ \text { Africa } & 1017(74.7) \\ \text { Others* }^{*} & 37(2.7)\end{array}$

Purpose of migration

$\begin{array}{ll}\text { Business } & 373(27.4) \\ \text { Study } & 872(64.0) \\ \text { Employment } & 117(8.6)\end{array}$

Cumulative stay in China

$\begin{array}{ll}1-6 \text { months } & 168(12.3) \\ 7-12 \text { months } & 123(9.0) \\ 1 \text { year and above } & 1071(78.6)\end{array}$

Duration of stay in China (December-February)

$\begin{array}{ll}1 \text { day-2 weeks } & 23(1.7) \\ 2 \text { weeks-1 month } & 21(1.5) \\ 1 \text { month-2 months } & 235(17.3) \\ 3 \text { months } & 1083(79.5)\end{array}$

Attitude towards the COVID-19 epidemic

Confident to protect themselves

\begin{tabular}{ll} 
Strongly agree & $832(61.1)$ \\
\hline Agree & $380(27.9)$ \\
Disagree & $134(9.8)$ \\
Strongly disagree & $16(1.2)$ \\
Worry about contracting COVID-19 & \\
Strongly disagree & $593(43.5)$ \\
Disagree & $197(14.5)$ \\
Agree & $279(20.5)$ \\
Strongly agree & $293(21.5)$
\end{tabular}

Worry about friends/loved ones contracting COVID-19

$\begin{array}{ll}\text { Strongly disagree } & 413(30.3) \\ \text { Disagree } & 156(11.5) \\ \text { Agree } & 259(19.0) \\ \text { Strongly agree } & 534(39.2) \\ \text { Feel helpless to prevent COVID-19 } & \\ \text { Strongly disagree } & 338(24.8) \\ \text { Disagree } & 544(39.9) \\ \text { Agree } & 373(27.4) \\ \text { Strongly agree } & 107(7.9) \\ \text { Confident that the epidemic will end soon } & \end{array}$

Continued 


\begin{tabular}{ll}
\hline $\begin{array}{l}\text { Table } 1 \\
\text { Variable }\end{array}$ & N (\%) \\
\hline Strongly agree & $529(38.8)$ \\
\hline Agree & $672(49.3)$ \\
Disagree & $105(7.7)$ \\
\hline Strongly disagree & $56(4.1)$ \\
Plan to leave China due to COVID-19 & \\
\hline No & $910(66.8)$ \\
\hline Yes & $148(10.9)$ \\
\hline Unsure & $304(22.3)$ \\
Social environment & \\
Chinese people's attitude towards foreigners & \\
\hline Very friendly & $250(18.4)$ \\
\hline Friendly & $574(42.1)$ \\
\hline Neutral & $449(33.0)$ \\
\hline Not friendly & $33(2.4)$ \\
Very unfriendly & $56(4.1)$ \\
Social support (mean $\pm S D)$ & $65.3 \pm 15.0$ \\
Study outcomes & $17.7 \pm 11.2$ \\
Depression (mean $\pm S D)$ & $65.9 \pm 14.4$ \\
Quality of life (mean $\pm S D)$ & $1.5 \pm 1.9$ \\
Alcohol use (mean $\pm S D)$ & \\
\hline
\end{tabular}

*Others refer to Europe, South America, North America and Oceania.

\section{DISCUSSION}

International migration is a global public health issue, and protecting the health and well-being of these migrants should become a priority. ${ }^{3817}$ This nationwide cross-sectional study of international migrants in China is the first study known to assess symptoms of depression, alcohol misuse and QoL among migrants during a public health emergency. The sampling of migrants using social media provided wide coverage of migrants hailing from more than 70 countries, who were in China during the COVID-19 epidemic.

The findings of our study suggest several key social determinants as correlates of well-being. First, among the migration characteristics measured, migrants from nonAsian countries reported lower depression, greater QoL and lower alcohol misuse relative to African migrants. This may reflect differences in exposures to stress or other factors associated with their migration process. People who migrated for business reported greater depression, perhaps reflecting the economic burdens expected for those who are attempting to transact business in China during the pandemic or reflect the difficulties of this activity in China. ${ }^{6}$

Attitudes towards COVID-19 emerged as key correlates across well-being outcomes. Public health outreach efforts that enhance awareness, reduce uncertainty related to the pandemic and inform the community how to effectively prevent infection are indicated. Programmes can engage international migrants in the cocreation of content, which can empower communities and enhance their integration within the host society. A focus on mental health and psychosocial responses, which may not be prioritised during COVID-19, may also address fears and uncertainties about the virus (Inter-Agency Standing Committee Reference Group on Mental Health and Psychosocial Support in Emergency Settings: Interim Briefing Note: Addressing mental health and psychosocial aspects of COVID-19 Outbreak, V.1.5).

The receiving country context is a key correlate of migrant well-being. ${ }^{33}$ Friendliness from local Chinese people, general perceived social support and trust in Chinese people, institutions and systems were protective factors for depression and associated with higher reported QoL. The association between friendly attitudes from locals was consistent with a previous study conducted before the COVID-19 pandemic among African migrants in China, which demonstrated local attitudes was a correlate of lower depression (under review). Similar to this study, the self-reported friendliness from locals was high $(60.5 \%)$, and only $6.5 \%$ of the population reported unfriendly attitudes ( $8 \%$ in the previous study). Perceived social support is a robust correlate of well-being among many migrant communities, and this finding is well supported in this literature. ${ }^{34-36}$

Migrant trust is an understudied topic, and it emerged as a key and robust correlate in this study. A dose-response relationship was observed such that greater levels of trust were associated with lower depression and higher QoL. Trust, a form of social capital, may be considered a vital resource for communities, especially among those occupying vulnerable and minority social positions. Enhancing the welfare of international migrants within China, and encouraging positive social exchange, is needed in order to achieve a key pillar of the Belt and Road Initiative, which is to enhance people-to-people bonds. ${ }^{19} 37$

Together, these results suggest that creating social spaces for migrants to integrate and overcome cultural differences, and programming to enhance trust through outreach and inclusion activities may safeguard the health of migrants. Community-based approaches that attempt to enhance community resilience, or community engagement with the broader social environment, may be useful to promote well-being among migrants. This approach may be especially worthwhile to consider within the broader context of south-south migration, where mental health services are largely underdeveloped and unavailable to migrants in particular. ${ }^{38}$

There are several study limitations. First, the crosssectional nature of the design limits causal inference. Second, the study was conducting following the onset of the COVID-19 outbreak, and therefore, preoutbreak mental health is not known. This was partially mitigated by the measurement and adjustment of previous mental health diagnosis and treatment. Third, the analytic sample was reduced for trust variables due to limitations 


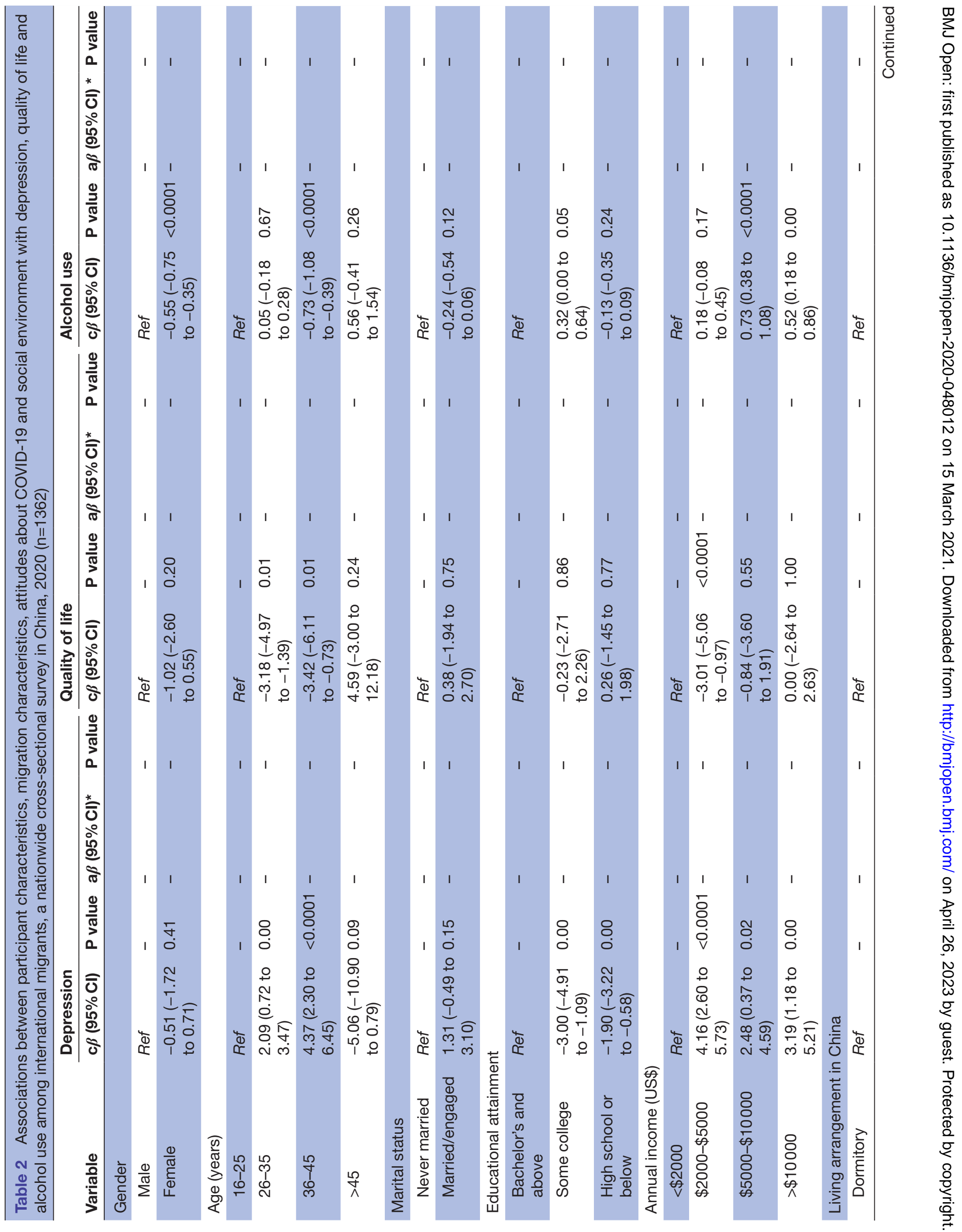




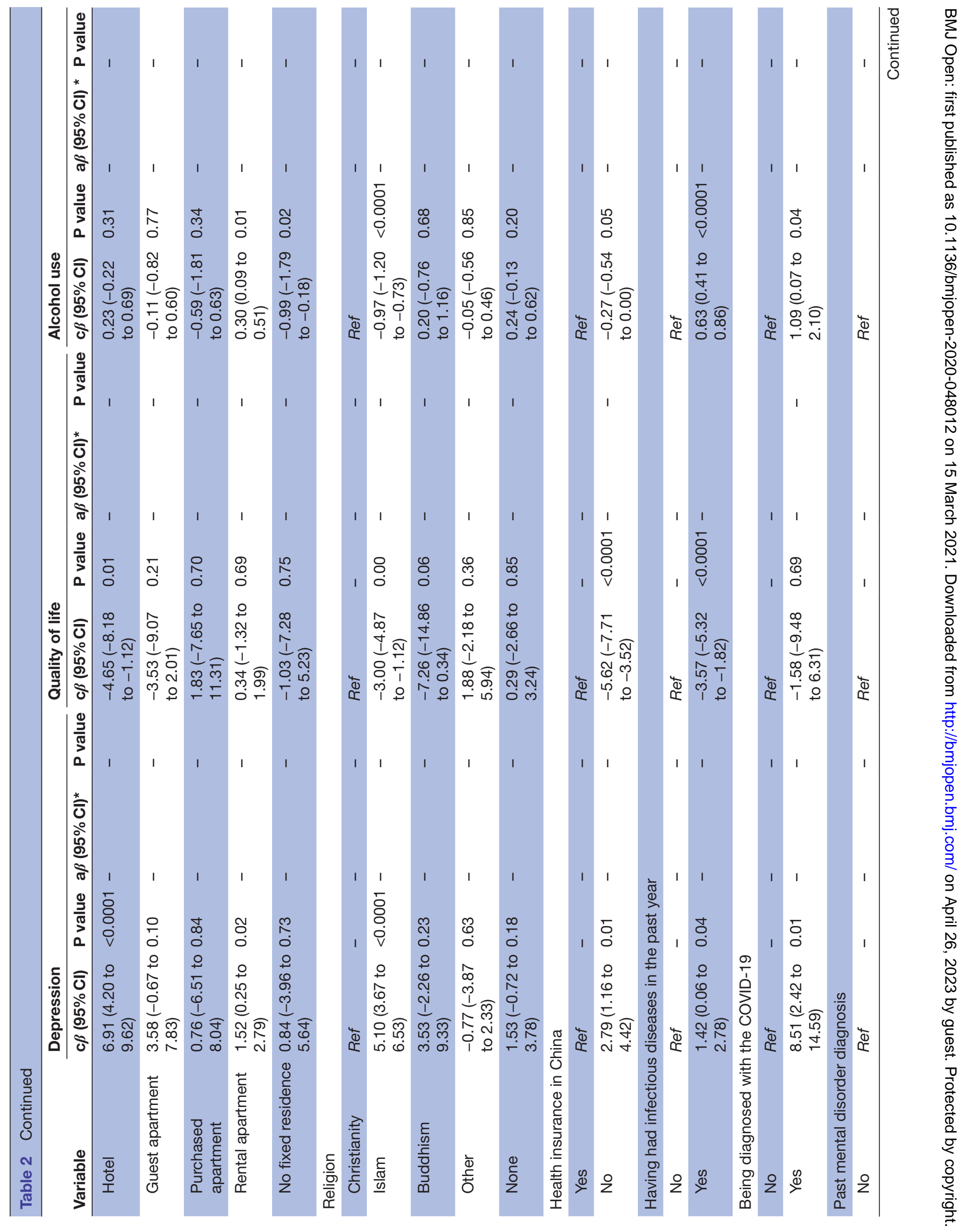




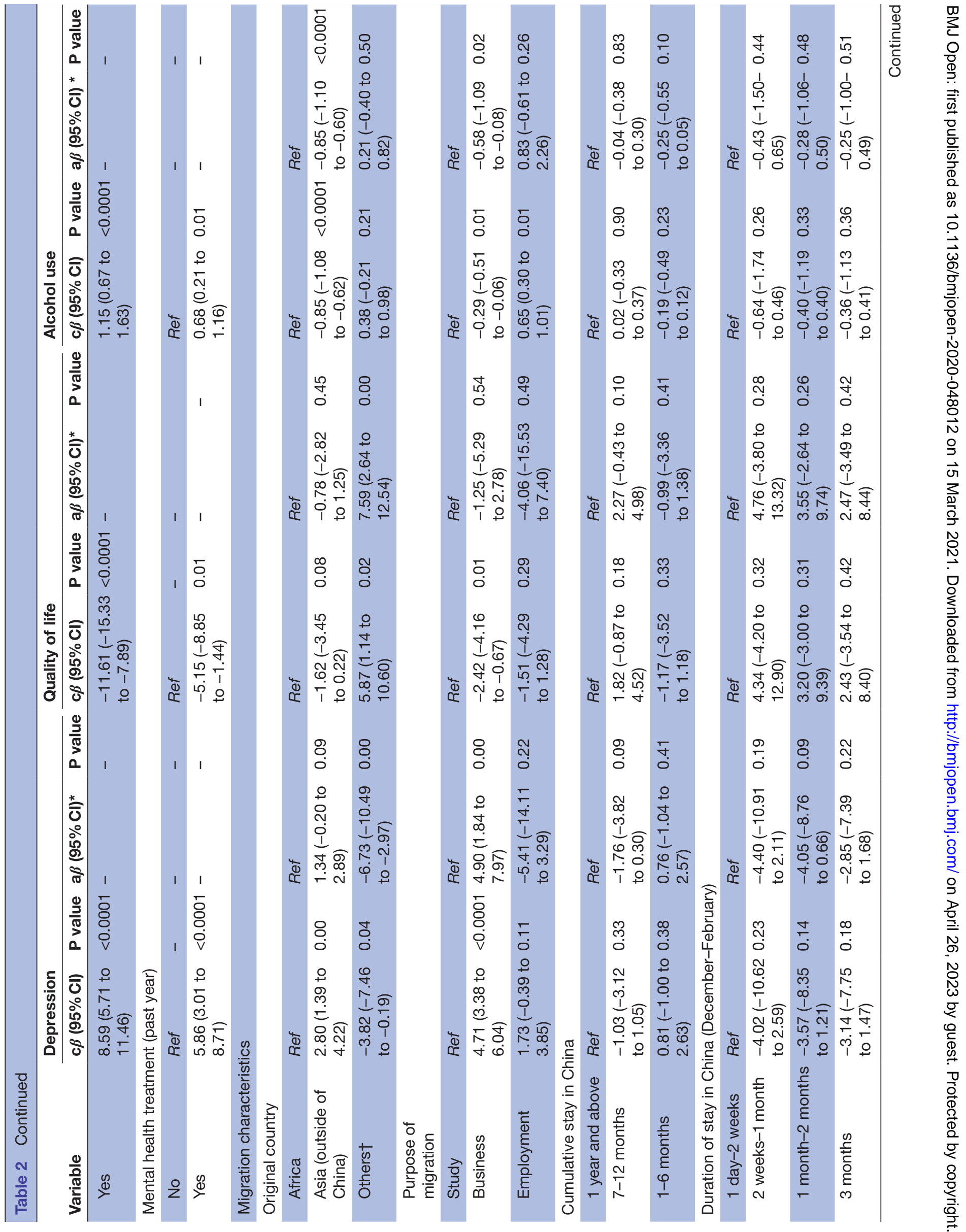




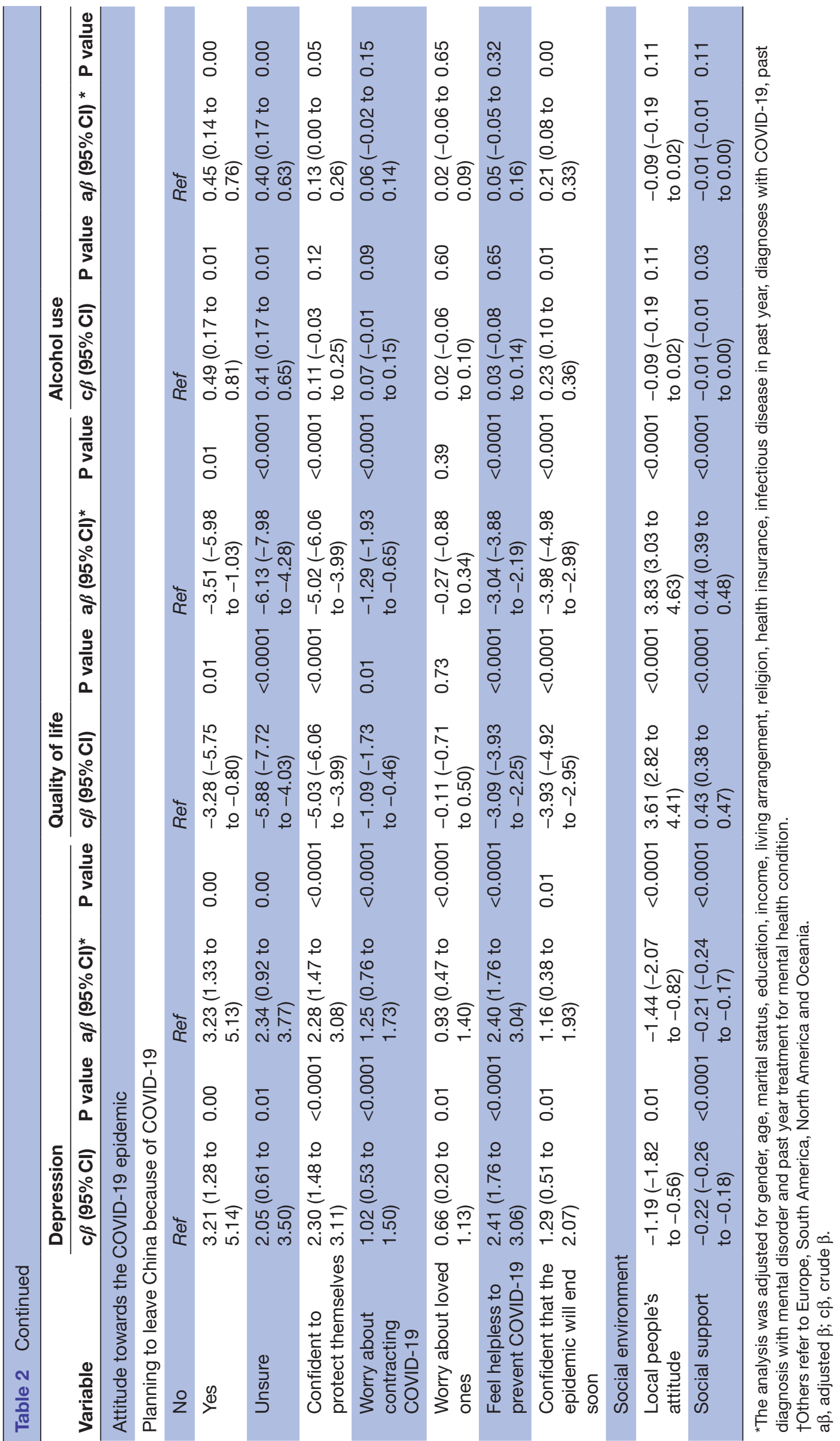




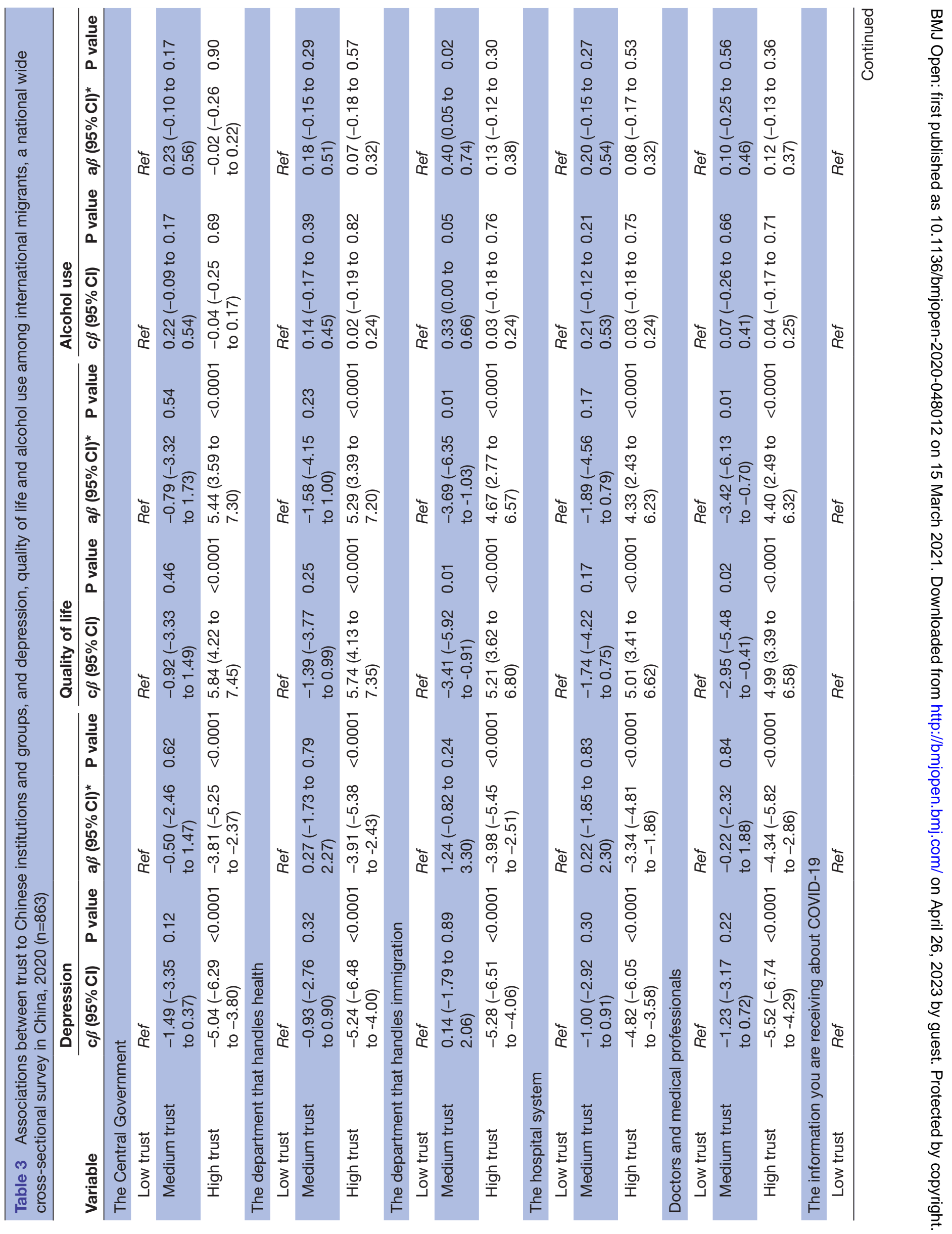




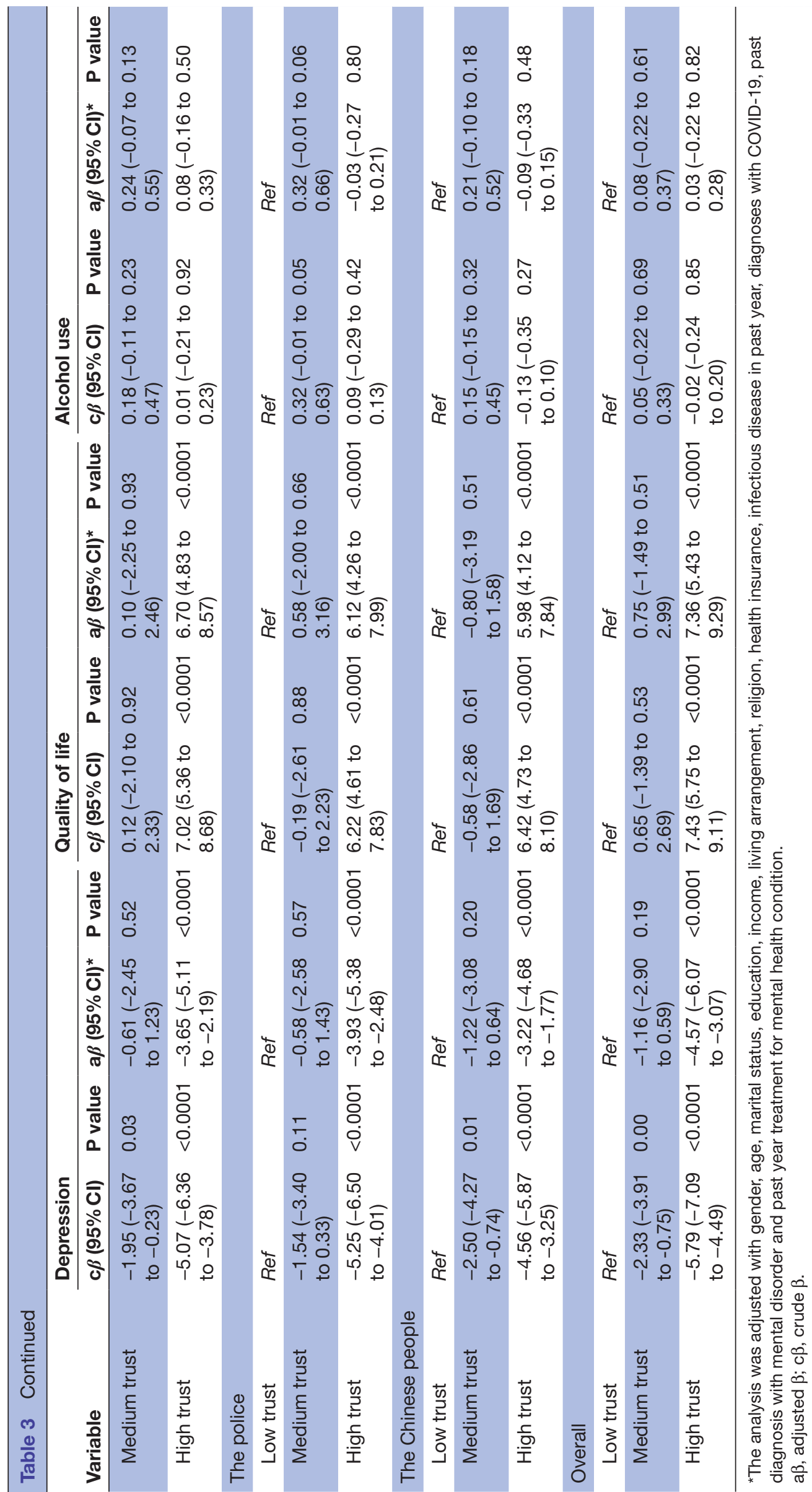


placed on the data collection that were outside of our control. The results were robust and unlikely to change qualitatively if a larger sample was obtained. Fourth, depression and alcohol use were not assessed with formal diagnostic interviews, which limits our ability to draw conclusions regarding population prevalence of these disorders during the epidemic, as screening instruments may not accurately reflect population prevalence. ${ }^{39}$ Fifth, the study population was composed of international migrants who were primarily students or traders, so inferences from this study may not generalise to other international migration populations with lower socioeconomic status or forced migrants. ${ }^{35}$ Sixth, the measures of trust in Chinese institutions and groups was deleted by the survey platform after responses were recorded from 868 individuals due to political sensitivity. Consequently, some significant differences between the sample who reported their trust and those who were unable to do so were observed. The group who reported trust date were younger, never married, less educated, had lower income, lived more frequently in dormitories, were comprised of more Christians and fewer Muslims, less frequently reported having health insurance, stayed in China longer, had reported lower depression and higher QoL compared with those who were unable to report their trust (see online supplemental table 4). The smaller trust sample may not be as representative of the larger population. Finally, although the study population includes people from multiple countries, selection bias due to non-response, the survey only in English and non-random sampling may affect the study inferences.

\section{CONCLUSIONS}

This was the first nationwide study known to evaluate the mental health and well-being of international migrants during a public health emergency. Findings from this study can guide efforts to build more effective public health approaches to reduce the burden of mental health among vulnerable populations within China and globally.

\section{Author affiliations}

${ }^{1}$ Department of Global Public Health, New York University Shanghai, Shanghai,

China

${ }^{2}$ Department of Health, Behavior, and Society, Johns Hopkins Bloomberg School of Public Health, Baltimore, Maryland, USA

${ }^{3}$ STD Control Department, Dermatology Hospital of Southern Medical University, Guangzhou, China

${ }^{4}$ STD Control Department, Southern Medical University Institute for Global Health and Sexually Transmitted Diseases, Guangzhou, China

Acknowledgements This work was supported by the Guangdong Medical Research Foundation (grant number A2019402). We would like to thank the international migrants included in this study for their participation and time.

Contributors CW and BJH conceived the study. CW, PZ, MZ and CL performed the survey. CW designed the analysis, interpreted the results and drafted an initial manuscript. PZ conducted the analysis. BJH, CL and BY edited and contributed content to the final draft.

Funding This work was supported by the Guangdong Medical Research Foundation (A2019402).
Competing interests None declared.

Patient consent for publication Obtained.

Ethics approval This study was approved by the University of Macau (SSHRE20APP008-FSS). An informed consent was obtained from all the participants who agreed to participate in this study.

Provenance and peer review Not commissioned; externally peer reviewed.

Data availability statement Data are available on reasonable request.

Supplemental material This content has been supplied by the author(s). It has not been vetted by BMJ Publishing Group Limited (BMJ) and may not have been peer-reviewed. Any opinions or recommendations discussed are solely those of the author(s) and are not endorsed by BMJ. BMJ disclaims all liability and responsibility arising from any reliance placed on the content. Where the content includes any translated material, BMJ does not warrant the accuracy and reliability of the translations (including but not limited to local regulations, clinical guidelines, terminology, drug names and drug dosages), and is not responsible for any error and/or omissions arising from translation and adaptation or otherwise.

Open access This is an open access article distributed in accordance with the Creative Commons Attribution Non Commercial (CC BY-NC 4.0) license, which permits others to distribute, remix, adapt, build upon this work non-commercially, and license their derivative works on different terms, provided the original work is properly cited, appropriate credit is given, any changes made indicated, and the use is non-commercial. See: http://creativecommons.org/licenses/by-nc/4.0/.

\section{ORCID iDs}

Peizhen Zhao http://orcid.org/0000-0002-9334-3744

Ming Zhou Xiong http://orcid.org/0000-0002-7146-1838

Cheng Wang http://orcid.org/0000-0001-8000-9969

\section{REFERENCES}

1 World Health Organization. Who characterizes COVID-19 as a pandemic. rolling updates on coronavirus disease (COVID-19), 2020. Available: https://www.who.int/emergencies/diseases/novelcoronavirus-2019/events-as-they-happen

2 Holmes EA, O'Connor RC, Perry VH, et al. Multidisciplinary research priorities for the COVID-19 pandemic: a call for action for mental health science. Lancet Psychiatry 2020;7:547-60.

3 Liem A, Wang C, Wariyanti Y, et al. The neglected health of international migrant workers in the COVID-19 epidemic. Lancet Psychiatry 2020;7:e20.

4 Lancet Migration. Global collaboration to advance migration health (2020). migration and COVID-19 resource platform, 2020. Available: https://www.migrationandhealth.org/

5 United Nations. Statistical Yearbook - 60th issue (2017 edition), 2017. Available: https://unstats.un.org/unsd/publications/statisticalyearbook/files/syb60/syb60.pdf

6 Hall BJ, Chen W, Latkin C, et al. Africans in South China face social and health barriers. Lancet 2014;383:1291-2.

7 Bakewell O. South-South Migration and Human Development: Reflections on African Experiences. In: Edited by programme UND, 2009.

8 Bodomo A, Liem A, Lin L, et al. How African migrants in China cope with barriers to health care. Lancet Public Health 2020;5:e192.

9 Bodomo AB, Ma G. From Guangzhou to Yiwu: emerging facets of the African diaspora in China. International Journal of African Renaissance Studies - Multi-, Inter- and Transdisciplinarity 2010;5:283-9.

10 Forum on China-Africa cooperation, 2020. Available: https://www. focac.org/eng/

11 Institute for Security and Development Policy. A new era of cooperation? Implications of the forum on China-Africa cooperation, 2018. Available: https://isdp.eu/new-era-cooperation-implicationsforum-china-africa-cooperation/

12 Ferdjani $\mathrm{H}$. African students in China: an exploration of increasing numbers and their motivations in Beijing, 2012. Available: http:// scholar.sun.ac.za/handle/10019.1/70764

13 Mathews G, Lin LD, Yang Y. The World in Guangzhou: Africans and other Foreigners in South China's global marketplace. Chicago: University of Chicago Press, 2017.

14 Bodomo A. The African trading community in Guangzhou: an emerging bridge for Africa-China relations. China $Q$ 2010;203:693-707.

15 Abubakar I, Aldridge RW, Devakumar D, et al. The UCL-Lancet Commission on migration and health: the health of a world on the move. The Lancet 2018;392:2606-54. 
16 Lindert J, Ehrenstein OSvon, Priebe S, et al. Depression and anxiety in labor migrants and refugees--a systematic review and metaanalysis. Soc Sci Med 2009;69:246-57.

17 Lin L, Brown KB, Hall BJ, et al. Overcoming barriers to health-care access: a qualitative study among African migrants in Guangzhou, China. Glob Public Health 2016;11:1135-47.

18 Lin L, Brown KB, Yu F, et al. Health care experiences and perceived barriers to health care access: a qualitative study among African migrants in Guangzhou, Guangdong Province, China. J Immigr Minor Health 2015;17:1509-17.

19 McLaughlin MM, Lee MC, Hall BJ, et al. Improving health services for African migrants in China: a health diplomacy perspective. Glob Public Health 2014;9:579-89.

20 Brooks SK, Webster RK, Smith LE, et al. The psychological impact of quarantine and how to reduce it: rapid review of the evidence. The Lancet 2020;395:912-20.

21 Chao M, Xue D, Liu T, et al. Media use and acute psychological outcomes during COVID-19 outbreak in China. J Anxiety Disord 2020;74:102248

22 UN. COVID-19 and human rights: we are all in this together, 2020. Available: https://www.un.org/victimsofterrorism/sites/www.un.org. victimsofterrorism/files/un_-_human_rights_and_covid_april_2020. pdf

23 International Organization for Migration (IOM). Guidelines to protect migrants in countries experiencing conflict or natural disaster. Geneva: IOM, 2016.

24 Hall BJ, Garabiles MR, Latkin CA. Work life, relationship, and policy determinants of health and well-being among Filipino domestic workers in China: a qualitative study. BMC Public Health 2019;19:229.

25 Hann D, Winter K, Jacobsen P. Measurement of depressive symptoms in cancer patients: evaluation of the center for epidemiological studies depression scale (CES-D). J Psychosom Res 1999;46:437-43.

26 Skevington SM, Lotfy M, O'Connell KA, et al. The world Health organization's WHOQOL-BREF quality of life assessment: psychometric properties and results of the International field trial. A report from the WHOQOL group. Qual Life Res 2004;13:299-310.

27 Cheung YB, Yeo KK, Chong KJ, et al. Reliability and validity of the English-, Chinese- and Malay-Language versions of the world Health organization quality of life (WHOQOL-BREF) questionnaire in Singapore. Ann Acad Med Singap 2017;46:461-9.
28 Colbourn T, Masache G, Skordis-Worrall J. Development, reliability and validity of the Chichewa WHOQOL-BREF in adults in Lilongwe, Malawi. BMC Res Notes 2012;5:346.

29 Redko C, Rogers N, Bule L, et al. Development and validation of the Somali WHOQOL-BREF among refugees living in the USA. Qual Life Res 2015;24:1503-13.

30 Puthoopparambil SJ, Bjerneld M, Källestål C. Quality of life among immigrants in Swedish immigration detention centres: a crosssectional questionnaire study. Glob Health Action 2015;8:28321.

31 World Health Organization. AUDIT: the Alcohol Use Disorders Identification Test : guidelines for use in primary health care, 2001. Available: https://apps.who.int/iris/handle/10665/67205

32 Zimet GD, Powell SS, Farley GK, et al. Psychometric characteristics of the multidimensional scale of perceived social support. J Pers Assess 1990;55:610-7.

33 Correa-Velez I, Gifford SM, Barnett AG. Longing to belong: social inclusion and wellbeing among youth with refugee backgrounds in the first three years in Melbourne, Australia. Soc Sci Med 2010;71:1399-408.

34 Hall BJ, Yang X, Huang L, et al. Barriers and facilitators of rapid HIV and syphilis testing uptake among Filipino transnational migrants in China. AIDS Behav 2020;24:418-27.

35 Chen W, Hall BJ, Ling L, et al. Pre-migration and post-migration factors associated with mental health in humanitarian migrants in Australia and the moderation effect of post-migration stressors: findings from the first wave data of the BNLA cohort study. Lancet Psychiatry 2017;4:218-29.

36 Li Q, Chi P, Hall BJ, et al. Job stress and depressive symptoms among migrant workers in Macau: a moderated mediation model of self-esteem and perceived social support. Psych J 2019;8:307-17.

37 Hall BJ, Zhang Y, Li K, et al. Domestic workers from the Philippines in China: an opportunity for health promotion within the belt and road initiative. J Immigr Minor Health 2020;22:1-2.

38 Hall BJ, Shi W, Garabiles MR, et al. Correlates of expected eMental health intervention uptake among Filipino domestic workers in China. Glob Ment Health 2018;5:e33.

39 Levis B, Benedetti A, loannidis JPA, et al. Patient health Questionnaire- 9 scores do not accurately estimate depression prevalence: individual participant data meta-analysis. J Clin Epidemiol 2020;122:115-28. 